\title{
Bighorn sheep show similar in-host responses to the same pathogen strain in two contrasting environments
}

\author{
Kezia Manlove ${ }^{1}$, Annette Roug ${ }^{2}$, Kylie Sinclair ${ }^{1}$, Lauren Ricci ${ }^{1}$, Kent Hersey $^{2}$, Cameron \\ Martinez ${ }^{3}$, Michael Martinez ${ }^{3}$, Kerry Mower ${ }^{4}$, Talisa Ortega ${ }^{3}$, Eric Rominger ${ }^{4}$, Caitlin \\ Ruhl $^{4}$, Nicole Tatman ${ }^{4}$, and Jace Taylor ${ }^{2}$ \\ ${ }^{1}$ Utah State University \\ ${ }^{2}$ Utah Division of Wildlife Resources \\ ${ }^{3}$ Taos Pueblo Division of Natural Resources \\ ${ }^{4}$ New Mexico Department of Game and Fish
}

May 18, 2021

\begin{abstract}
Ecological context - the particular environment, and how it shapes mixing dynamics and individual susceptibility surrounding infectious disease events - can have major bearing on epidemic outcomes, yet directly comparable disease events with contrasting ecological contexts are relatively rare in wildlife systems due to concurrent differences in host genetics or pathogen strain. Here, we present a case study of one such event: a spillover of a "goat-clade" Mycoplasma ovipneumoniae strain into one bighorn sheep population that played out against two very different ecological backdrops. One event occurred on the herd's home range near the Rio Grande Gorge in New Mexico, while the other progressed in a captive facility at Hardware Ranch in Utah. We collected data on antibody and pathogen load patterns through time at the individual level, and examined demographic responses to pathogen invasion to compare the intensity of, and in-host responses to, infection in both settings. While data collection regimens varied between the two sites, general patterns of antibody expansion and gross timing of symptoms were consistent. Symptoms emerged in the captive setting 12.9 days post-exposure, and we estimated an average time to seroconversion among the captive animals of 24.9 days. Clinical signs peaked among the captive animals at approximately 36 days post-infection, consistent with subsequent declines in symptom intensity in the free-ranging herd. At the captive site, older animals exhibited more severe declines in body condition as determined through declines in loin thickness, higher symptom burdens, and a decelerated antibody response to the pathogen. Younger animals were more likely than older animals to clear infection at or before the time of sampling at both sites. This study presents one of the richest datasets on immune responses in bighorn sheep over the course of a newly introduced M. ovipneumoniae strain available to-date.
\end{abstract}

\section{Hosted file}

HardwareRGGDiseaseEvent_Submitted.pdf available at https://authorea.com/users/414358/ articles/522408-bighorn-sheep-show-similar-in-host-responses-to-the-same-pathogenstrain-in-two-contrasting-environments

\section{Hosted file}

Hardware_GraphicalAbstract.pdf available at https://authorea.com/users/414358/articles/ 522408-bighorn-sheep-show-similar-in-host-responses-to-the-same-pathogen-strain-in-twocontrasting-environments 